\title{
вмЈ Global Health Interventions addressing men, masculinities and gender equality in sexual and reproductive health and rights: an evidence and gap map and systematic review of reviews
}

\author{
Eimear Ruane-McAteer, ${ }^{\oplus 1,2}$ Avni Amin, ${ }^{3}$ Jennifer Hanratty, ${ }^{2}$ Fiona Lynn, ${ }^{1,2}$ \\ Kyrsten Corbijn van Willenswaard, ${ }^{1,2}$ Esther Reid, ${ }^{1}$ Rajat Khosla, ${ }^{3}$ Maria Lohan ${ }^{\odot 1,2}$
}

To cite: Ruane-McAteer E, Amin A, Hanratty J, et al. Interventions addressing men, masculinities and gender equality in sexual and reproductive health and rights: an evidence and gap map and systematic review of reviews. BMJ Global Health 2019;4:e001634. doi:10.1136/ bmjgh-2019-001634

Handling editor Sanne Peters

- Additional material is published online only. To view please visit the journal online (http://dx.doi.org/10.1136/ bmjgh-2019-001634).

Received 10 April 2019 Revised 26 July 2019 Accepted 27 July 2019

Check for updates

(C) Author(s) (or their employer(s)) 2019. Re-use permitted under CC BY. Published by BMJ.

${ }^{1}$ School of Nursing and Midwifery, Queen's University Belfast, Belfast, United Kingdom ${ }^{2}$ Centre for Evidence and Social Innovation (CESI), Queen's University Belfast, Belfast, United Kingdom ${ }^{3}$ Department of Reproductive Health and Research (RHR), World Health Organization, Geneve, Switzerland

\section{Correspondence to} Professor Maria Lohan; m.lohan@qub.ac.uk

\begin{abstract}
Objectives Working with men/boys, in addition to women/ girls, through gender-transformative programming that challenges gender inequalities is recognised as important for improving sexual and reproductive health and rights (SRHR) for all. The aim of this paper was to generate an interactive evidence and gap map (EGM) of the total review evidence on interventions engaging men/boys across the full range of WHO SRHR outcomes and report a systematic review of the quantity, quality and effect of gendertransformative interventions with men/boys to improve SRHR for all.
\end{abstract}

Methods For this EGM and systematic review, academic and non-academic databases (CINAHL, Medline, PsycINFO, Social Science Citation Index-expanded, Cochrane Library, Campbell Collaboration, Embase, Global Health Library and Scopus) were searched using terms related to SRHR, males/masculinities, systematic reviews and trials (January 2007-July 2018) with no language restrictions for review articles of SRHR interventions engaging men/ boys. Data were extracted from included reviews, and AMSTAR2 was used to assess quality. Outcomes were based on WHO reproductive health strategy.

Results From the 3658 non-duplicate records screened, the total systematic reviews of interventions engaging men/boys in SRHR was mapped through an EGM ( $n=462$ reviews) showing that such interventions were relatively evenly spread across low-income (24.5\%), middle-income (37.8\%) and high-income countries (37.8\%). The proportion of reviews that included gender-transformative interventions engaging men/boys was low $(8.4 \%, 39 / 462)$, the majority was in relation to violence against women/girls ( $n=18 / 39$, $46.2 \%$ ) and conducted in lower and middle-income countries ( $n=25 / 39,64 \%$ ). Reviews of gender-transformative interventions were generally low/critically low quality $(n=34 / 39,97.1 \%)$, and findings inconclusive $(n=23 / 39$, $59 \%)$, but $38.5 \%(n=15 / 39)$ found positive results.

Conclusion Research and programming must be strengthened in engagement of men/boys; it should be intentional in promoting a gender-transformative approach, explicit in the intervention logic models, with more robust experimental designs and measures, and supported with qualitative evaluations.

\section{Key questions}

What is already known?

- Engagement of men/boys alongside women in gender-transformative programming is fundamental to addressing gender inequality and sexual and reproductive health and rights (SRHR) for all.

What are the new findings?

- The paper offers the first interactive evidence and gap map of the total systematic review evidence on interventions engaging men/boys mapped across the full range of WHO SRHR outcomes.

- A minority of reviews included gender-transformative interventions with men/boys (8.4\%, 39/462 reviews), of which $39 \%$ reported positive results, but the majority was mixed or inconclusive, and the overall reporting quality of reviews was low.

- Review evidence engaging men/boys is approximately equally prevalent in low-income, middle-income and high-income countries, but gender-transformative approaches with men/boys is particularly likely to be found in low-income and middle-income countries.

What do the new findings imply?

- Future research and programming with men/boys needs to promote a gender-transformative approach, explicit in the intervention logic models, with more robust experimental designs and measures, supported with qualitative evaluations.

- Greater partnership is required between programme implementers and researchers in order to realise the potential for engaging men/boys in promoting gender equality to improve SRHR for all.

\section{INTRODUCTION}

The case for addressing gender equality as part of a human rights-based approach to improving health, including sexual and reproductive health (SRH), has been a longstanding guiding principle in the feminist 
literature on gender and development and significantly foregrounded in global public health since before the 1994 International Conference on Population and Development (ICPD) in Cairo. ${ }^{1-9}$ The conference marked a paradigm shift in global health away from an overarching concern with population control in low-resource countries to a human rights-based approach aimed at empowering women to control their fertility and their access to safe childbearing, while making explicit too the need to engage men to make this a reality.

Since then, too, the focus on addressing gender inequality in health programming has become more clearly conceptualised as a gender-transformative approach. The concept of gender-transformative approaches was first coined by Dr Geeta Rao Gupta ${ }^{10}$ in the context of the HIV/AIDS epidemic and has since gained traction in international health and development policy. ${ }^{6} 1112$ The WHO defines a gender-transformative approach as one 'that address the causes of gender-based health inequities through approaches that challenge and redress harmful and unequal gender norms, roles, and power relations that privilege men over women'. ${ }^{11}$ Men are also implicated in the harmful consequences of gender inequality, harming their own and other men's health and the health of their female partners as a result of narrow and constraining definitions of what it means to be a man, therefore gender-transformative approaches also benefit men in broadening the interpretation of masculinity and the socially acceptable ways in which masculinity can be expressed. ${ }^{13} 14$

Just as in the original definition offered by Rao Gupta, the WHO definition of a gender-transformative approach is derived from considering a continuum of approaches to addressing gender equality in health programming. In the $\mathrm{WHO}^{15}$ definition, these are: a gender unequal approach that perpetuates gender inequality by reinforcing unbalanced norms, roles and relations; a genderblind approach that ignores gender norms, roles and relations and thereby often reinforces gender-based discrimination; a gender-sensitive approach that considers gender norms, roles and relations but does not address inequality generated by unequal norms, roles or relations; a gender-specific approach that considers women's and men's specific needs or roles but does not seek to change these roles; and a gender-transformative approach that considers gender norms, roles and relations for women and men, as does gender-specific and gender-sensitive, but is distinguished by the imperative to challenge gender inequality. A gender-transformative approach seeks to challenge gender inequality by transforming harmful gender norms, roles and relations through inclusion in programming of strategies to foster progressive changes in power relationships between women and men.

The underpinning rationale of addressing gender inequality is because it is a key determinant of the health of men and women of all gender identities and sexualities yet generally disproportionately disadvantages the opportunities and outcomes for women and girls, including in the particular field of sexual and reproductive health and rights (SRHR). ${ }^{16-22}$ However, a gender-transformative approach also prompts an explicit focus on the roles of men/boys in transforming gender inequality to improve men's health and especially SRHR. There is increasing recognition that men and boys can play a role as either supporting and championing or damaging and denying the health and rights of women and girls. Hence, focusing on boys/men through a gender-transformative approach goes beyond a men's health focus or the inclusion of men as partners of women with respect to SRH decision making. ${ }^{23-31}$ Despite more than a decade of gender-transformative programming on engaging men/ boys in several areas of health including SRHR, there is a paucity of evidence on the effectiveness of interventions to improve SRHR outcomes; how best to engage men/boys from a gender-transformative perspective; and what works and for which SRHR health outcomes. Therefore, when considering how best to promote SRHR globally through gender-transformative programming, it is important to take stock of the evidence and identify policy, programme and research implications.

The aim of this paper is to first generate an interactive evidence and gap map (EGM) of the total systematic review evidence of interventions engaging men/boys mapped across the full range of WHO SRHR outcomes and to identify those reviews that contain gender-transformative interventions relating to each SRHR outcome. This leads to the second aim of this paper, which is to report a systematic review of the quantity, quality and effect of gender-transformative interventions with men/ boys to improve SRHR. Our exclusion of programmes/ interventions that we considered not to be gender-transformative does not mean such interventions are not of value or have not shown promise. The choice to focus on identifying gender-transformative interventions, and not the entire WHO continuum from gender unequal to gender-specific, was, however, informed by global policy interest in addressing gender inequality in health programming.

We addressed the following questions:

1. What is the state of the evidence on interventions designed to engage men/boys across all WHO SRHR outcomes?

2. What is the proportion of these interventions that are explicitly gender-transformative?

3. What is the methodological quality of gender-transformative interventions with men/boys?

4. To what extent are gender-transformative interventions with men/boys effective in positively impacting SRHR outcomes?

\section{METHODS}

The decision to conduct a review of reviews rather than of primary intervention studies was guided by the necessity of including the broad scope of all seven WHO defined SRHR outcomes (listed below). For the EGM, we 
searched CINAHL, Medline, PsycINFO, Social Science Citation Index-expanded, Cochrane Library, Campbell Collaboration, Embase, Global Health Library, Scopus and Google Scholar for systematic reviews (1 January 2007-31 July 2018). There were no language restrictions. Bibliographies of included reviews were screened. The search dates were based on a previous WHO review of the evidence. ${ }^{32}$ Review papers deemed eligible for inclusion were systematic reviews synthesising findings from experimental studies (randomised controlled trials (RCTs)/quasi-experimental) that included men/boys and assessed the effect on SRHR outcomes. The decision to include reviews including RCTs and quasi-experimental studies only was based on the need to evaluate high-quality evidence on intervention effectiveness. If a review included additional non-experimental studies, data were only extracted for experimental studies. A review was considered systematic when it contained a systematic search, characterised by the reporting of a predetermined search strategy, specifying the location of the search and stating the numbers and reasons for excluding papers from the final synthesis (eg, Preferred Reporting Items for Systematic Reviews and Meta-Analyses (PRISMA) flow chart). The population of interest included males of all ages, irrespective of sexual orientation. Comparators included either no interventions, services as usual or alternative services.

The eligibility criteria for the systematic review of gender-transformative interventions was as above, but limited to the subset of reviews that included interventions using a gender-transformative approach, that is, included evaluations of interventions that included ways to transform harmful gender norms, gender practices, gender inequality and/or addressed the causes of gender-based inequities within the interventions. ${ }^{11}$ Where reviews did not exclusively focus on gender-transformative interventions, data were extracted for relevant gender-transformative interventions only.

We operationalised the $\mathrm{WHO}^{15}$ definition of gender-transformative programming:

- Considers gender norms, roles and relations for women and men and that these affect access to and control over resources.

- Considers women's and men's specific needs.

- Addresses the causes of gender-based health inequities.

- Includes ways to transform harmful gender norms, roles and relations.

- The objective is often to promote gender equality.

- Includes strategies to foster progressive changes in power relationships between women and men.

Each review and any additional data tables and appendices were read by two authors independently to identify elements of interventions that were articulated as transforming gender norms, masculinity norms and/or unequal power relations between women and men. Hence, to the extent possible in an exercise of this nature relying on review level descriptions of interventions in a peer-reviewed article, we extracted gender-transformative interventions as per the definition provided by WHO. ${ }^{15}$ Current reviewers did not rely on included review authors' classifications of a review being gender-transformative or not. online supplementary appendix 1 includes a list of included reviews categorised as gender-transformative; this list is subcategorised based on the intent of the review, that is, category A: reviews that explicitly sought to include gender-transformative interventions and category B: reviews that did not explicitly seek to identify gender-transformative interventions for their reviews, yet at least one gender-transformative intervention was included due to a focus in the review on an outcome, such as HIV or domestic violence, where evaluations of gender-transformative interventions have been conducted.

The SRHR outcomes of interest were based on the WHO Reproductive Health Strategy ${ }^{33}$ :

1. Helping people realise their desired family size (contraception and family planning; prevention and treatment of infertility).

2. Ensuring the health of pregnant women/girls and their new-born infants (maternal and infant mortality; preventing complications in pregnancy, childbirth and postnatal period).

3. Preventing unsafe abortion.

4. Promoting sexual health and well-being (prevention of reproductive tract and sexually transmitted infections; HIV/AIDS; and interventions promoting sexual well-being, for example, treatments for erectile dysfunction. Excluding conditions not acquired sexually, for example, testicular and prostate cancers and more general men's health conditions)

5. Promoting SRH in disease outbreaks (prevention of sexual transmission of Zika and Ebola viruses).

6. Promoting healthy adolescence for a healthy future (covering all SRHR outcomes with a specific focus on adolescents).

7. Preventing and responding to violence against women/girls (intimate partner violence (IPV); domestic violence and sexual coercion/violence) and harmful practices (ie, female genital mutilation; child, early and forced marriage; and IPV in males).

Search terms related to SRHR were adapted from a previous systematic review of SRH interventions in humanitarian crises conducted by Warren and colleagues. ${ }^{34}$ Terms related to males and masculinities were developed and tested in a number of databases. An edited Pearl Harvesting string was used to identify systematic review papers. ${ }^{35}$ Search terms are reported in online supplementary appendix 2 . This review title was registered, ${ }^{36}$ and protocol was published ${ }^{37}$ with the Campbell Collaboration.

\section{Data analysis}

Four authors (ER-M, ML, KCvW and ER) and one trained researcher (Dr Conall O'Rourke, see Acknowledgements) applied the inclusion and exclusion criteria 
when screening titles, abstracts and full-text results for eligibility using Distiller Systematic Review Software (2017). One author arbitrated disagreement. Inter-rater reliability score was considered acceptable; at full-text screening, the weighted overall kappa score was 0.60 (original kappa) and 0.97 after moderation.

Double-blind data extraction was conducted by two authors (ER-M and $\mathrm{KCvW}$ ). The outcomes of interest in the EGM were: WHO outcome domains; types of studies included (RCTs only or mixed designs); study resource setting (high/middle/low-income countries, as per World Bank categorisations, ${ }^{38}$ and whether the approach in the review identified gender-transformative interventions or not (online supplementary appendix 3)). However, in nine of the included reviews, insufficient intervention detail was available at review level to extract individual intervention-level data.

For the reviews engaging men/boys through a gender-transformative approach, we extracted the above information along with key components and theoretical rationale of interventions included, settings and participants, key findings and recommendations of the reviews (online supplementary appendix 4).

The AMSTAR2 tool $^{39}$ was used to assess the methodological quality of the subset of reviews including interventions that used a gender-transformative approach with men. Double-blind quality assessment was conducted by two reviewers ( $\mathrm{KCvW}$ and $\mathrm{FL}$ ) with an inter-rater reliability of $83.2 \%$ achieved for individual items, with full agreement in the overall rating of quality for each included systematic review. Any differences in the appraisal of individual items were discussed until agreement was reached.

\section{Role of the funding source}

The review was funded through a grant from the WHO Human Reproduction Programme (HRP) that specialises in SRHR research. Staff from HRP specialising in gender equality and human rights provided technical oversight on the study design, data analysis and data interpretation. The corresponding author had full access to all the data in the study and had final responsibility for the decision to submit for publication. Findings were presented to the WHO HRP Gender and Rights Advisory Panel (GAP) in January 2019, composed of international experts in gender equality and human rights in SRHR. The GAP provided further inputs on the findings of the review.

\section{RESULTS}

On screening of 3658 non-duplicate records and fulltext screening of 662 full texts, 462 eligible reviews on engaging men/boys in SRHR were included in the EGM. Thirty-nine of the systematic reviews reported on gender-transformative interventions that engaged men/boys and were included in the systematic review of reviews. Figure 1 illustrates the PRISMA flow chart documenting search, screening and reasons for exclusion.
Findings responding to the first question (ie, the state of the evidence on interventions designed to engage men/boys across all SRHR outcomes) are presented as an EGM. The EGM, with a visual interactive summary of all systematic reviews involving men/boys to improve SRHR, categorised under the identified seven WHO SRHR outcome domains, can be accessed here: http:/ / srhr.org/masculinities/rhoutcomes/. This EGM also identifies the reviews that contain gender-transformative interventions. A second EGM further categorising the same data by resource settings (high-income countries (HICs); middle-income countries (MICs); and low-income countries (LICs)) is provided in http://srhr.org/ masculinities/wbincome/.

The EGM results demonstrate that the overall review evidence on engaging men/boys in improving SRHR had a relatively balanced spread across economic context. Over one-third of the total review evidence on engaging boys/men in SRHR is in HICs ( $\mathrm{n}=242$ reviews), over one-third in MICs ( $\mathrm{n}=242$ reviews) and approximately one quarter in LICs ( $\mathrm{n}=157$ reviews). However, the EGM results demonstrate that the evidence on engagement of men/boys varies considerably across the SRHR outcomes. The WHO SRHR outcomes with the greatest quantity of review evidence on engaging men/boys are: promoting sexual health and well-being (68.2\% of reviews), followed by those measuring outcomes related to desired family size $(31.4 \%)$ and healthy adolescence $(25.1 \%)$. Fewer reviews covered outcomes related to violence against women/girls $(14.5 \%)$ and health of pregnant women and children $(9.1 \%)$. Only two reviews were found that looked at outcomes related to preventing unsafe abortion and no reviews looked at SRH in disease outbreaks (table 1).

Turning to the second question relating to the evidence for gender-transformative approaches with men, a very small proportion of reviews engaging men/ boys contained gender-transformative interventions. Of the 462 reviews, only 39 (8.4\% total reviews) included an intervention engaging men/boys in SRHR adopting a gender-transformative approach (online supplementary appendix 5). The greatest imbalance in reviews including gender-transformative interventions engaging men/boys (as measured by the ratio of gender-transformative to non-gender-transformative reviews in each WHO SRHR domain) is for outcomes related to promoting sexual health, desired family size and healthy adolescence (table 1). Of significance, however, reviews of interventions addressing violence against women/girls (VAWG) are almost equally likely to be gender transformative than non-gender transformative. Also, the gender-transformative review evidence engaging men/boys in SRHR was more likely to be from low-income and middle-income countries (LMICs) with fewer from HICs. Only 14 of the 39 reviews $(35.9 \%)$ contained studies from HICs.

Focusing on the 39 reviews of gender-transformative interventions engaging men/boys, we summarise their characteristics in terms of their aims, number 


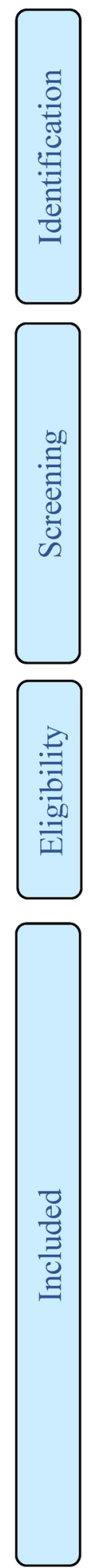
Records identified through database searching
$(\mathrm{n}=9229)$

Additional records identified through other sources $(n=22)$

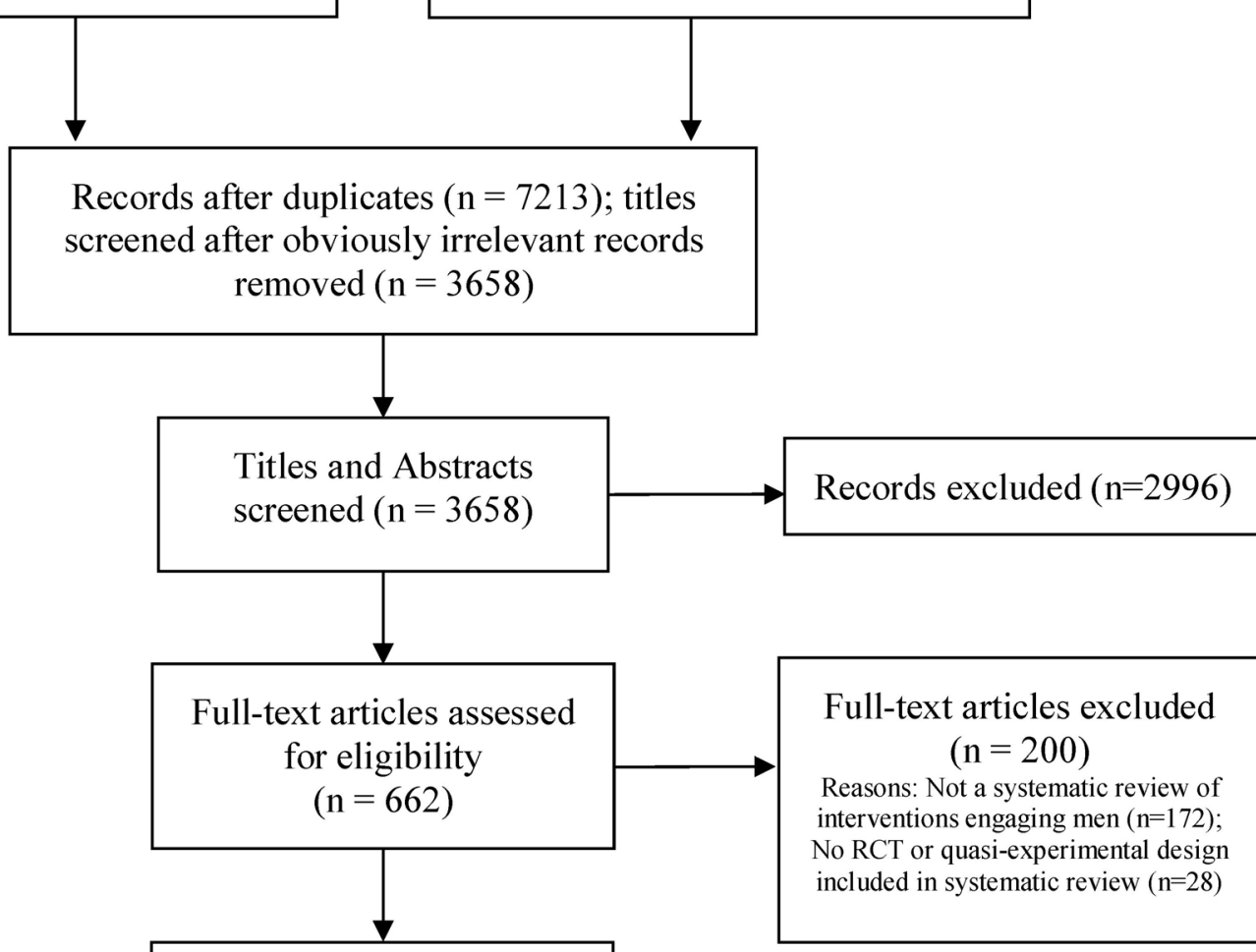

Studies included in evidence and gap map:

Systematic review of RCT/Quasi interventions including men $(\mathrm{n}=462)$

Figure 1 PRISMA flow diagram. RCTs, randomised controlled trials.

of gender-transformative interventions included, study designs and outcomes, methodological quality (AMSTAR2 score) and conclusions about effectiveness (table 2). The majority of reviews including gender-transformative interventions were rated low or critically low quality $(n=34)$, largely due to inadequate reporting of methodological details. The agreed ratings for each item of AMSTAR2, as well as the overall rating of included reviews can be found in online supplementary appendix 6 . As the checklist was designed to assess the methodological quality of systematic reviews, it was not applicable for assessing four papers identified as reviews of reviews. ${ }^{40-43}$

Although a number of reviews addressed outcomes spanning multiple domains, reviews were categorised 
Table 1 Reviews on engaging men in relation to WHO sexual and reproductive health and rights outcomes and the proportion of which is gender-transformative

\begin{tabular}{|c|c|c|}
\hline WHO SRHR outcome & $\begin{array}{l}\text { Number and percentage of } \\
\text { outcomes observed across all } \\
\text { reviews ( } n=462)^{*}\end{array}$ & $\begin{array}{l}\text { Ratio of gender transformative } \\
\text { to non-gender transformative }\end{array}$ \\
\hline Promoting sexual health and well-being & $315(68.2 \%)$ & $1: 16.5$ \\
\hline Desired family size & $145(31.4 \%)$ & $1: 12.2$ \\
\hline Healthy adolescence & $116(25.1 \%)$ & $1: 5.8$ \\
\hline Health of pregnant women, infants and girls & $42(9.1 \%)$ & $1: 5.0$ \\
\hline Preventing unsafe abortion & $2(0.4 \%)$ & - \\
\hline $\begin{array}{l}\text { Sexual and reproductive health in disease outbreaks (ie, } \\
\text { Ebola and Zika) }\end{array}$ & $0(0)$ & - \\
\hline
\end{tabular}

${ }^{*}$ Reviews could cover multiple domains. Percentages of reviews in outcome domains were calculated as a percentage of the total number of reviews $(n=462)$, for example, 315 of 462 reviews $(68.2 \%)$ contained interventions on promoting sexual health and well-being. $\mathrm{SRHR}$, sexual and reproductive health and rights.

into each WHO domain based on their primary outcome. The most commonly combined interventions addressed HIV and VAWG. ${ }^{24} 445$ The prevention of VAWG was the primary outcome most studied in reviews including gender-transformative interventions $(46.2 \%, \mathrm{n}=18)$. In contrast to the EGM, where promoting sexual health and well-being, was most frequently reported, a much smaller number of reviews of gender-transformative interventions reported on this outcome $(23.1 \%, \mathrm{n}=9)$ but, nonetheless, was the second most studied outcome.

Few reviews specifically disaggregated for outcomes related to male adolescent SRH. Within helping people realise their desired family size, only two reviews included interventions focusing on contraception, ${ }^{46}{ }^{47}$ and no reviews of gender-transformative interventions were identified relating to (in)fertility. Two reviews examined the impact of engaging men/boys in gender-transformative interventions on maternal and new-born health. ${ }^{49}$ Finally, consistent with the EGM of total review evidence, no reviews of gender-transformative interventions were identified for which the primary outcome was preventing unsafe abortion or SRH in disease outbreaks (table 3).

Evidence of effectiveness is largely inconclusive yet promising. The majority of reviews reported mixed or inconclusive results relating to the effectiveness of engaging men/boys through gender-transformative approaches in SRHR (table 4). However, a third of reviews reported positive or promising outcomes, and only one review reported no effect. ${ }^{50}$ While no adverse effects were reported on SRHR outcomes in engaging men through gender-transformative approaches, two reviews in maternal and new-born health ${ }^{48}{ }^{49}$ cautioned that the impact of some of these interventions on women's autonomy remained ambiguous. This was especially true where health professionals and fathers were more educated than mothers underlying the imperative to examine for unintended effects on generating gender equalities.
Overall, however, the quality of evidence on effectiveness is limited for several reasons, including lack of critical mass of high-quality experimental gender-transformative intervention studies and limited studies including behavioural (eg, VAWG rates) or biological (eg, HIV status) outcomes. More of the included studies relied on outcomes based on self-reported attitudinal and norm changes and were measured over a limited time period (ie, under 1-year duration), which do not necessarily correlate or translate into behaviour change outcomes.

\section{DISCUSSION}

To our knowledge, this is the first comprehensive EGM reporting evidence on engaging men/boys from across the range of SRHR topics considered under the WHO reproductive health strategy. ${ }^{33}$ It is also the first systematic review of the impact of engaging men/boys through a gender-transformative approach on SRHR outcomes. The EGM highlights that while the majority of review evidence on male engagement lies in areas of sexual health, family planning and adolescent SRHR outcomes, there is very limited review evidence on topics related to maternal and child health, VAWG, unsafe abortion and SRH in disease outbreaks. Geoeconomically, the majority of the interventions engaging men/boys included in reviews is in LMICs.

The findings with most significant concerns for policy, research and programming relate to the limited number of reviews that include intervention studies that are gender-transformative (ie, that address harmful masculinities, male privilege over women or unequal power relations between women and men). The only outcome where the ratio of gender-transformative to non-gender-transformative reviews is approaching 1:1, and which a majority of the gender-transformative reviews cover, is in VAWG, which highlights the need for intentional and explicit promotion of gender equality and gender-transformative programming with men/boys. 


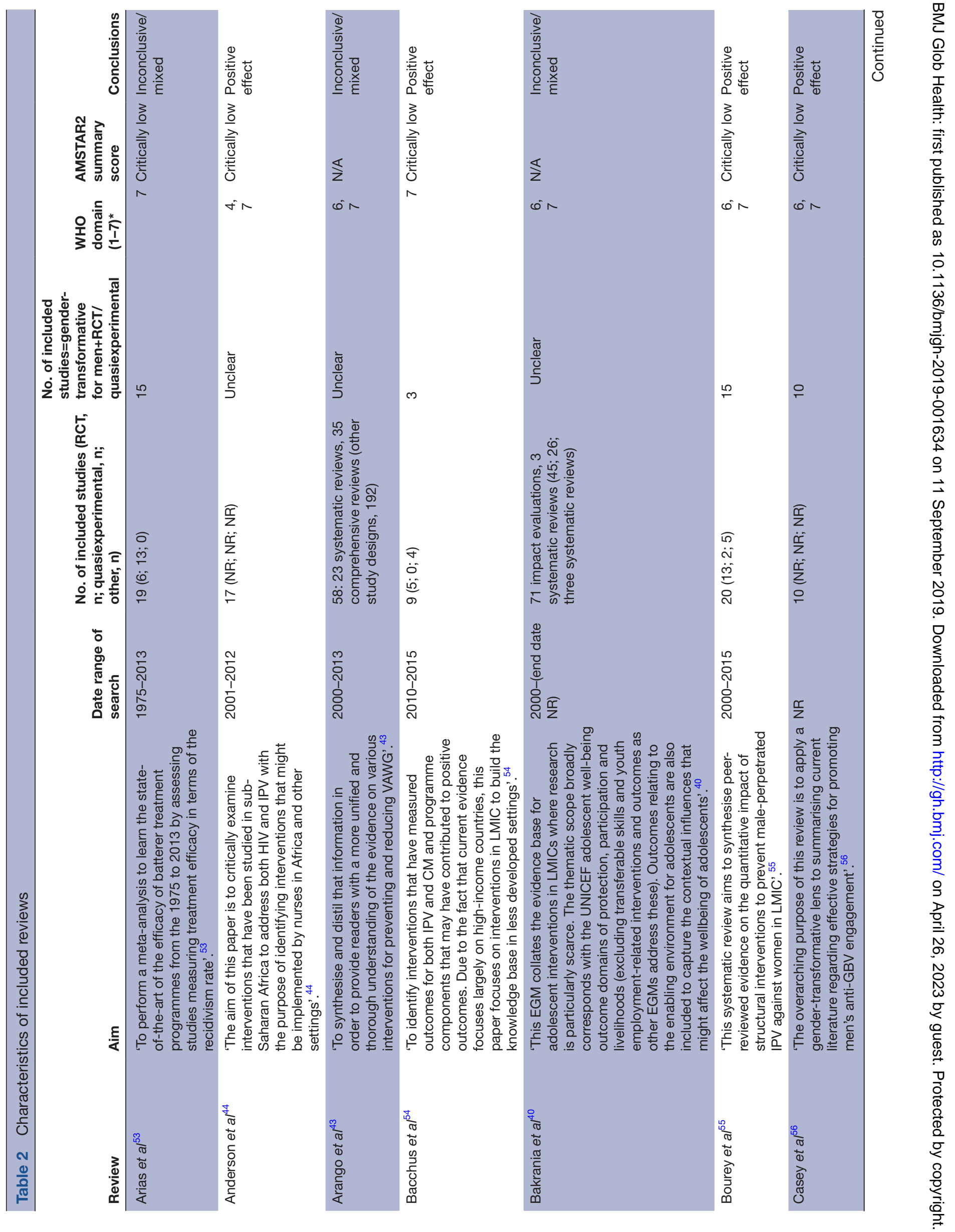




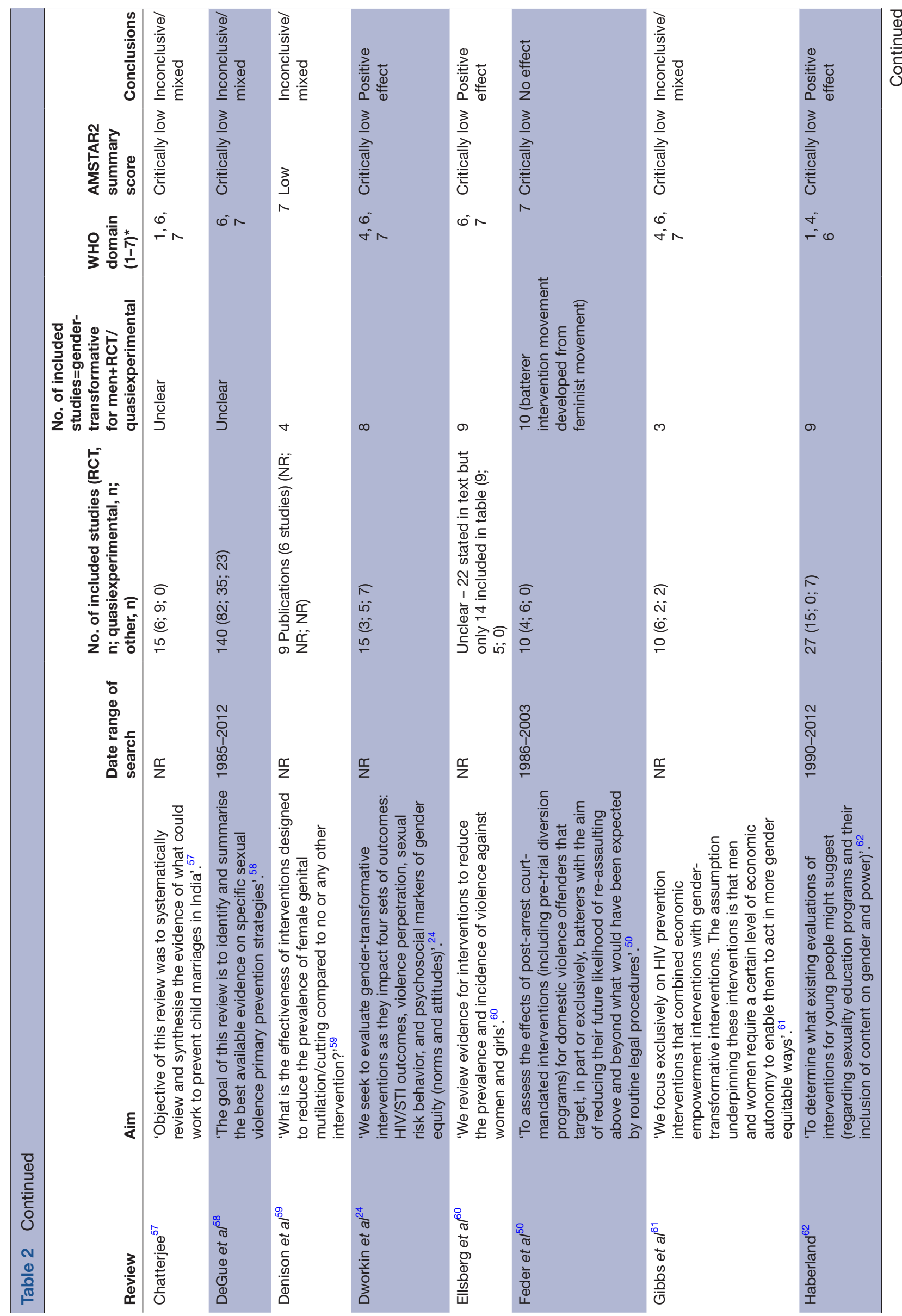




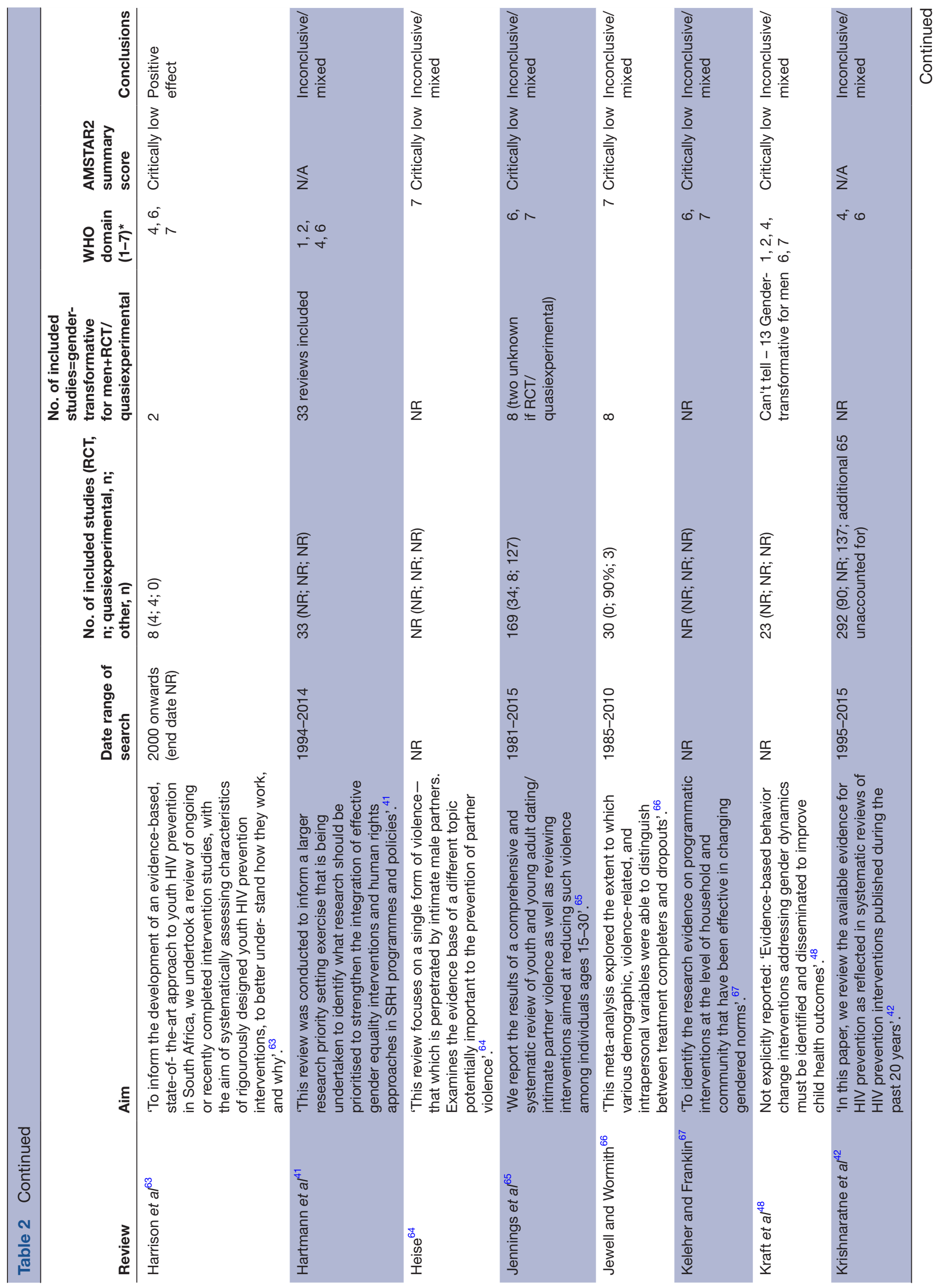



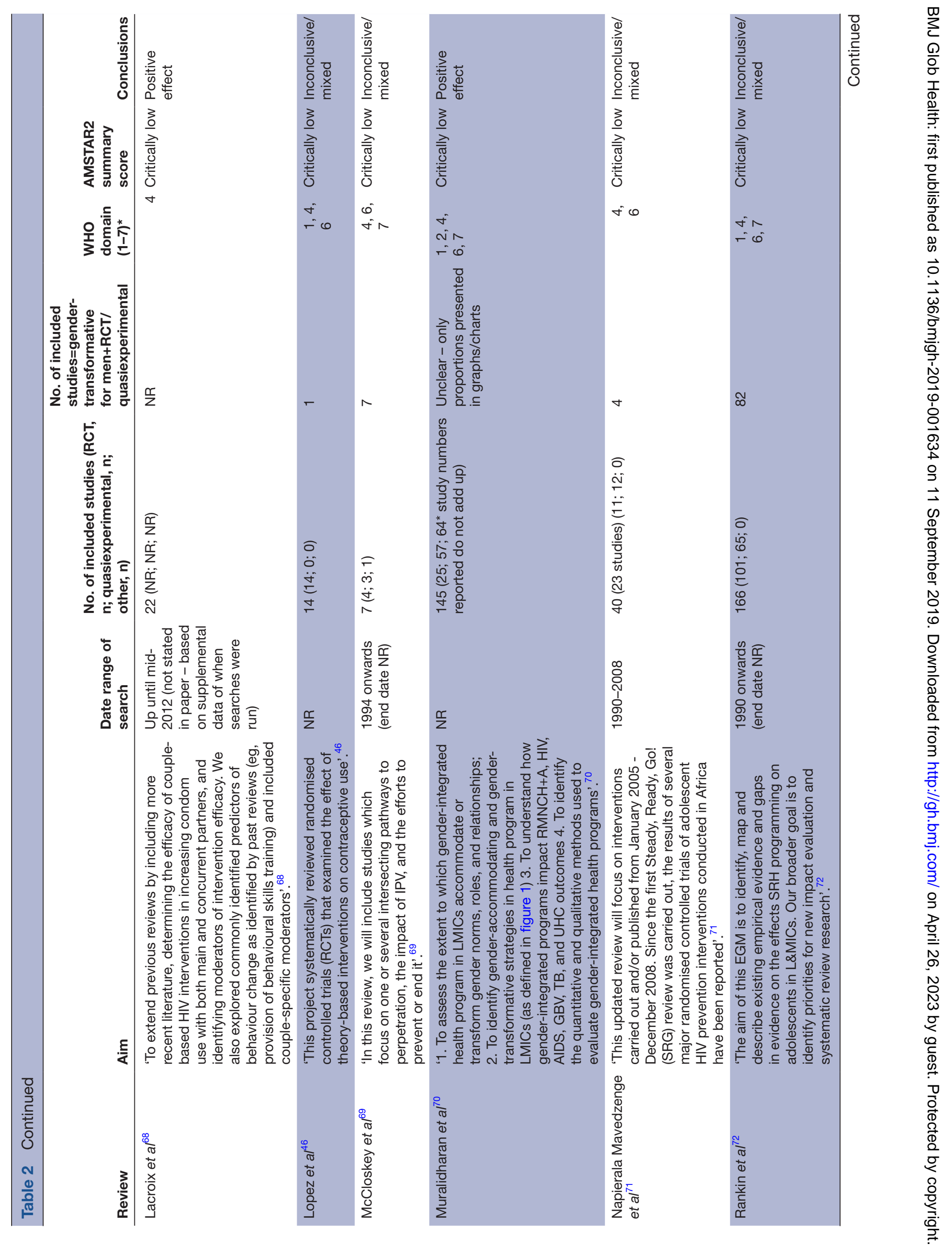


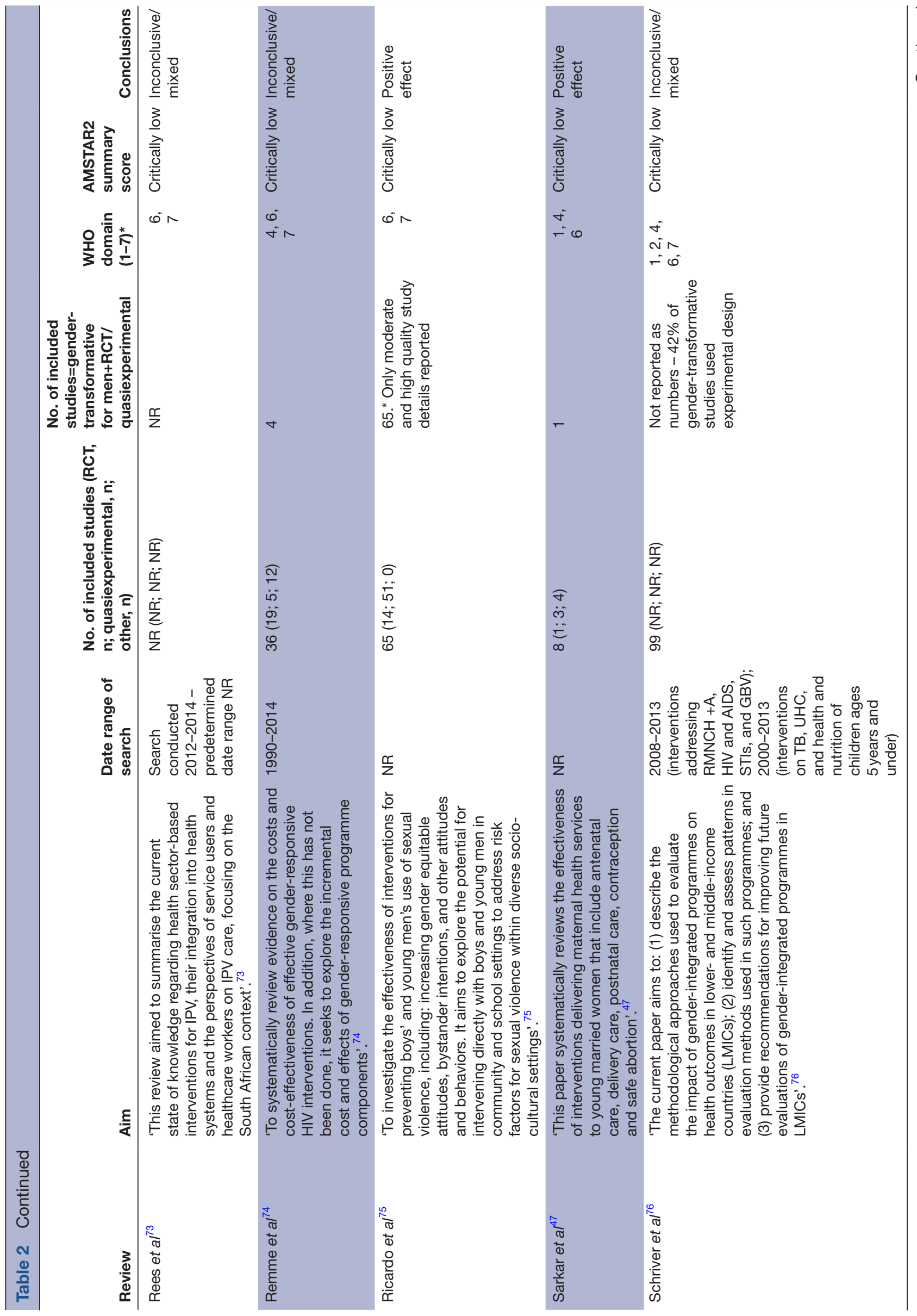



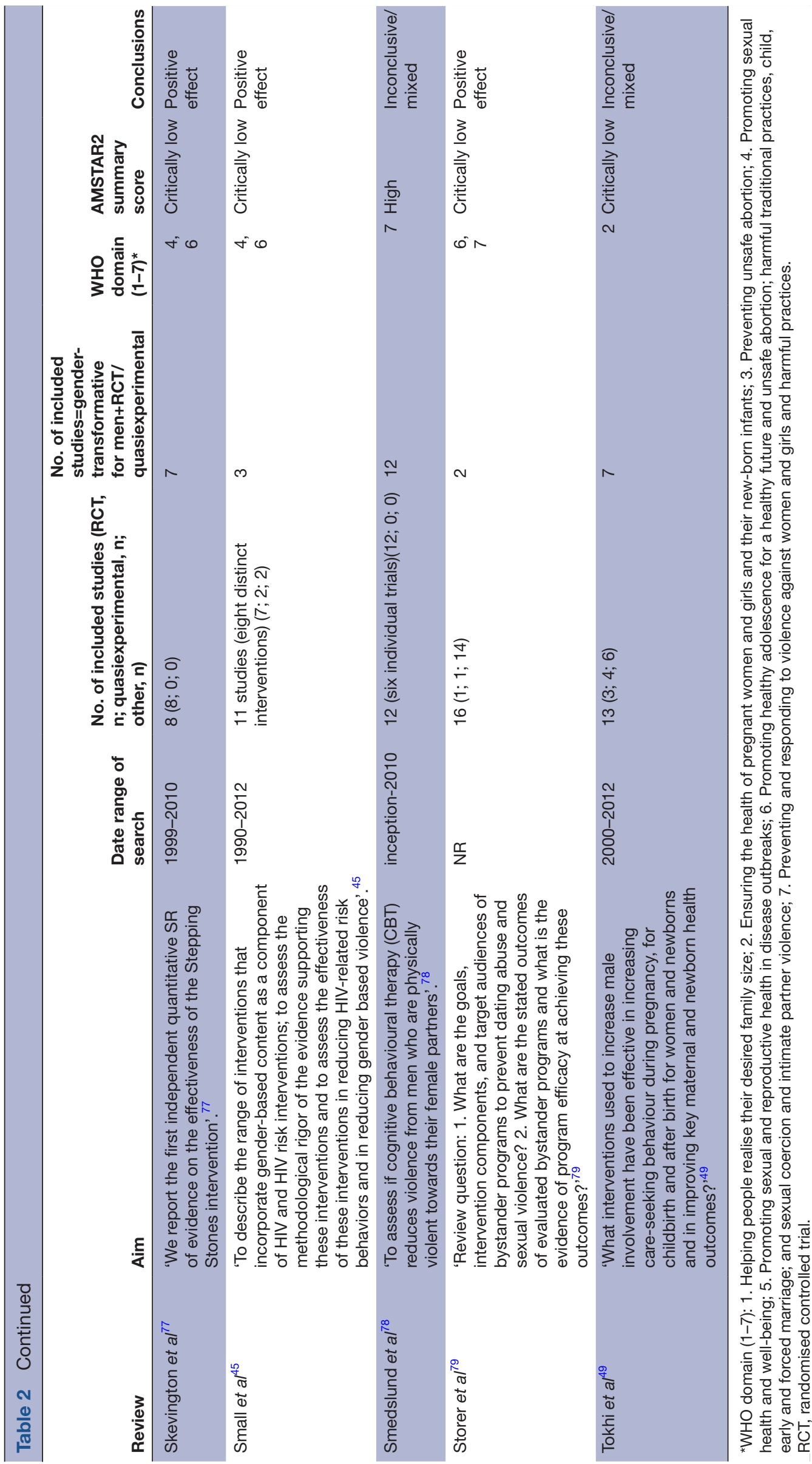
Table 3 Number of reviews of gender-transformative interventions covering each WHO SRHR domain

Primary SRHR outcome covered in reviews ( $n$ of

WHO SRHR domain $39, \%$ of reviews) ${ }^{\star}$

\begin{tabular}{ll}
$\begin{array}{l}\text { 1. Preventing and responding to } \\
\text { violence against women/girls }\end{array}$ & $18(46.2)$ \\
$\begin{array}{l}\text { 2. Promoting sexual health and } \\
\text { well-being }\end{array}$ & $9(23.1)$ \\
$\begin{array}{l}\text { 3. Promoting healthy adolescence } \\
\text { for a healthy future }\end{array}$ & $4(10.3)$ \\
$\begin{array}{l}\text { 4. Helping people realise their } \\
\text { desired family size }\end{array}$ & $2(5.1)$ \\
$\begin{array}{l}\text { 5. Health of pregnant women/girls } \\
\text { and their new-born infants }\end{array}$ & $2(5.1)$ \\
$\begin{array}{l}\text { 6. Preventing unsafe abortion } \\
\text { 7. Sexual and reproductive health } \\
\text { in disease outbreaks (ie, Ebola and } \\
\text { Zika) }\end{array}$ & $0(0)$ \\
\hline
\end{tabular}

*Additional category created for synthesis: Promotion of Gender Equality and Resulting SRHR Outcomes ( $\mathrm{n}=4,10.3 \%)$.

SRHR, sexual and reproductive health and rights.

The lack of gender-transformative work engaging men/ boys, particularly in the area of SRHR, is a concern for a number of reasons. First, engaging men/boys in SRHR without explicit attention to gender inequalities can, at worst, be harmful particularly when it comes to undermining women's rights and autonomy, or even where it is neutral or blind to these realities, can continue to perpetuate the status quo of gender inequalities. Second, as this review shows, the assumption that engaging men/boys in SRHR in and of itself can promote gender equality is false and needs to be challenged. Closer examination is required of the premise/aim of the intervention, the theory of change and whether there is explicit attention to issues of male privilege, power and positionality in relation to women.

Moreover, almost 25 years after the ICPD call for male engagement as an approach to promoting gender equality, the findings of this review highlight that the evidence remains sparse in terms of rigour and quality and in demonstrating conclusively the effectiveness on a range of SRHR outcomes. Encouragingly, approximately $40 \%$ of the reviews containing gender-transformative interventions showed positive findings on one or more outcomes and few showed negative outcomes. However,

Table 4 Concluded direction of results from included reviews for a gender-transformative approach to sexual and reproductive health interventions $(n=39)$

\begin{tabular}{lc}
\hline Inconclusive/mixed & $23(59 \%)$ \\
Positive effect & $15(38.5 \%)$ \\
No effect & $1(2.6 \%)$ \\
\hline
\end{tabular}

Table 2 and online supplementary file 1 identify each review conclusion and details of their included interventions. findings should be interpreted with caution in light of low-quality review evidence. This highlights that with more rigorous study designs and outcome measures used, as well as attention to programme and evaluation quality and reporting, progress is likely.

\section{CONCLUSION}

Analysis of the review evidence provides direction for a strengthened research agenda. First, there is a need to strengthen programme reporting standards when it comes to reviews and studies-as it is obvious from table 2 that many of the parameters were not reported or unclear while extracting data. Second is the need for future studies to go beyond self-reported attitudinal outcomes by men and include more biobehavioural outcomes. Third is the need for evaluations to have a longer period of time for programme effects to show results downstream. Fourth is the need for programme implementers and researchers to be explicit about the pathways by which change is likely to occur. Finally, the limited number of higher quality intervention studies (ie, quasi-experimental or RCT design), particularly those gender-transformative in nature, highlights the need for investment in more rigorous approaches.

A number of limitations of this review warrant acknowledgement. A general limitation of a review of reviews is there is a risk of missing newer evidence from interventions that have not yet been included in systematic reviews. ${ }^{51}$ Although language was not a limit applied, no non-English language reviews of gender-transformative interventions were identified, possibly a result of only English language search terms used. The focus on effectiveness limited our selection to experimental and quasi-experimental studies, omitting cross-sectional and solely qualitative studies.

In conclusion, the review demonstrates we have not yet reached a tipping point in gender-transformative work with men/boys to improve SRHR outcomes. The next generation of investments in research and programming on male engagement needs to consolidate this emerging evidence and assess SRHR outcomes that are less well covered such as maternal and new-born health, family planning, safe abortion, infertility and SRH in disease outbreaks. Research and programming needs to be intentional in promoting gender equality and monitoring any adverse or unexpected outcomes that may result from interventions. Gender-transformative programming requires a balance between appealing to men in order to effectively engage with them and challenging men to contest gender inequalities. ${ }^{52}$ Efforts should focus on exploring the characteristics of interventions where promising or positive results were found in order to further unpack what approaches to male engagement with gender-transformative programming are likely to be most effective, the pathways of change and the types of outcomes that can provide better measures of what works. Furthermore, triangulation with qualitative data highlighting where and how change might have taken place in men's attitudes and behaviours is important. This 
requires greater partnership between programme implementers and researchers in order to realise the potential for engaging men/boys in promoting gender equality for SRHR.

Acknowledgements We wish to acknowledge the support of $\mathrm{Dr}$ Conall 0'Rourke (PhD), Matthew Johnston (BSc) and Reem Saeed Alghamdi (PhD candidate) for their support with initial data screening. Also thanks to Jeff Brunton, Research Officer, EPPI-Centre, University College London, for support in producing the maps using EPPI Reviewer: http://eppi.ioe.ac.uk/cms/er4

Contributors All authors designed the protocol and review procedures. ER-M conducted database search and removed obviously irrelevant records under the guidance of JH. ER-M, KCvW, ER and ML and trained data screeners (Dr Conall O'Rourke, Matthew Johnston, Reem Saeed Alghamdi, see Acknowledgements) screened records for inclusion. ER-M and KCvW conducted review of review data extraction. KCvW and FL conducted data extraction for quality appraisal. ER-M and $M L$ conducted initial analysis of the findings. ER-M and $M L$ drafted the manuscript. $\mathrm{AA}, \mathrm{JH}, \mathrm{FL}, \mathrm{KCVW}, \mathrm{ER}$ and RK provided critical revisions to the manuscript. All authors read and approved the final manuscript.

Funding This review is funded by the Human Reproduction Programme (United Nations Development Plan, UNDP/United Nations Population Fund, UNFPA/UNICEF/ WHO/World Bank Special programme of research, development and research training in human reproduction - HRP) at the WHO).

Competing interests None declared.

Patient consent for publication Not required

Provenance and peer review Not commissioned; externally peer reviewed.

Data availability statement All data relevant to the study are included in the article or uploaded as supplementary information.

Open access This is an open access article distributed in accordance with the Creative Commons Attribution 4.0 Unported (CC BY 4.0) license, which permits others to copy, redistribute, remix, transform and build upon this work for any purpose, provided the original work is properly cited, a link to the licence is given, and indication of whether changes were made. See: https://creativecommons.org/ licenses/by/4.0/.

\section{REFERENCES}

1. Petchesky RP. Global prescriptions: gendering health and human rights. London \& New York: Zed books, 2003.

2. Pulerwitz J, Michaelis A, Verma R, et al. Addressing gender dynamics and engaging men in HIV programs: lessons learned from horizons research. Public Health Rep 2010;125:282-92.

3. Gender CR. Health and theory: Conceptualizing the issue, in local and world perspective. Soc Sci Med 2012;74:1675-83.

4. Tallis V. Power To: Local Action. In: Feminisms, HIV and AIDS [Internet. London: Palgrave Macmillan UK, 2012: 172-89. (cited 2018 May 1).

5. Agarwal B. The power of numbers in gender dynamics: illustrations from community forestry groups. J Peasant Stud 2015;42:1-20. [Internet].

6. DFID PPA Learning Partnership Group. A Theory of Change on Gender Equality \& Women's and Girls' Empowerment [Internet], 2015

7. Jewkes R, Flood M, Lang J. From work with men and boys to changes of social norms and reduction of inequities in gender relations: a conceptual shift in prevention of violence against women and girls. The Lancet 2015;385:1580-9. [Internet].

8. Gender KN. Poverty, and inequality: a brief history of feminist contributions in the field of international development. Gend Dev 2015;23:189-205. [Internet].

9. Pearse R, Connell R. Gender norms and the economy: insights from social research. Fem Econ 2015

10. Gupta GR. Gender, sexuality, and HIV/AIDS: the what, the why, and the how. Can HIVIAIDS policy law Rev [Internet] 2000;5:86-93.

11. World Health Organization. Gender mainstreaming for health managers: a practical approach - Participant's Notes [Internet] Geneva, 2011

12. Greaves L, Pederson A, Poole N. Making it better: gender transformative health promotion. Ontario: Canadian Scholars' Press, 2014

13. Dworkin SL, Fleming PJ, Colvin CJ. The promises and limitations of gender-transformative health programming with men: critical reflections from the field. Cult Heal Sex 2015.
14. The Lancet Child \& Adolescent Health. The lost boys. Lancet Child Adolesc Heal [Internet] 2019;3.

15. World Health Organization W. Gender mainstreaming for health managers: a practical approach [Internet. Geneva: World Health Organization, 2011.

16. Gakidou E, Cowling K, Lozano R, et al. Increased educational attainment and its effect on child mortality in 175 countries between 1970 and 2009: a systematic analysis. The Lancet 2010;376:959-74. [Internet].

17. Weldon SL, Htun M. Feminist mobilisation and progressive policy change: why governments take action to combat violence against women. Gender \& Development 2013;21:231-47.

18. Upadhyay UD, Gipson JD, Withers M, et al. Women's empowerment and fertility: a review of the literature. Soc Sci Med 2014;115:111-20.

19. Inhorn MC, Patrizio P. Infertility around the globe: new thinking on gender, reproductive technologies and global movements in the 21st century. Hum Reprod Update 2015;21:411-26.

20. Barot S. Sexual and reproductive health and rights are key to global development: The case for ramping up investment [Internet]. The Guttmacher Institute, 2015. Available: https://www.guttmacher.org/ sites/default/files/article_files/gpr180101.pdf

21. Kågesten A, Gibbs S, Blum RW, et al. Understanding factors that shape gender attitudes in early adolescence globally: a mixedmethods systematic review. PLoS One 2016;11:e0157805.

22. Amin A, Chandra-Mouli V. Empowering adolescent girls: developing egalitarian gender norms and relations to end violence. Reprod Health 2014;11:11-13.

23. Dudgeon MR, Inhorn MC. Men's influences on women's reproductive health: medical anthropological perspectives. Soc $\mathrm{Sci}$ Med 2004;59:1379-95. [Internet]

24. Dworkin SL, Treves-Kagan S, Lippman SA. Gender-transformative interventions to reduce HIV risks and violence with heterosexuallyactive men: a review of the global evidence. AIDS Behav 2013;17:2845-63.

25. Higgins JA, Hoffman S, Dworkin SL, et al. and Women's Vulnerability to HIV/AIDS. Am J Public Health 2010;100:435-45. [Internet]

26. Marsiglio W, Lohan M, Culley L. Framing Men's Experience in the Procreative Realm. J Fam Issues 2013.

27. Levtov R, Van Der Gaag N, Greene M, et al. State of the World's Fathers 2015: A MenCare Advocacy Publication. Promundo 2015.

28. Promundo. Helping Dads Care [Internet], 2016

29. Assaf S, Davis LM. Does Men's Involvement Improve the Health Outcomes of Their Partners and Children? [Internet]. Rockville, Maryland, USA. 64. Report No: DHS Analytical Studies, 2018.

30. Lohan M. Advancing research on men and reproduction. Int J Mens Health 2015;14:214-32.

31. Lohan $\mathrm{M}$, Aventin Áine, Clarke $\mathrm{M}$, et al. Can teenage men be targeted to prevent teenage pregnancy? A feasibility cluster randomised controlled intervention trial in schools. Prev Sci 2018;19:1079-90.

32. WHO. Engaging men and boys in changing gender-based inequity in health: Evidence from programme interventions. World Heal Organ Libr [Internet], 2007

33. World Health Organization (WHO). Reproductive health strategy to accelerate progress towards the attainment of international development goals and targets [Internet. Geneva: World Health Organization, 2004. (cited 2018 May 1).

34. Warren E, Post N, Hossain M, et al. Systematic review of the evidence on the effectiveness of sexual and reproductive health interventions in humanitarian crises. BMJ Open 2015;5:e008226.

35. Sandieson R. Pathfinding in the research forest: the pearl harvesting method for effective information retrieval. Educ Train Dev Disabil 2006;41:401-9.

36. Hanratty J, Amin A, Ruane-McAteer E, et al. Title registration: interventions addressing men, masculinities and gender equality in sexual and reproductive health an evidence and gap map and systematic review of reviews. Campbell Syst Rev [Internet] 2018;2018.

37. Ruane-McAteer E, Hanratty J, Lynn F, et al. Protocol: Interventions addressing men, masculinities and gender equality in sexual and reproductive health: An evidence and gap map and systematic review of reviews. Campbell Syst Rev [Internet], 2018. Available: https://www.campbellcollaboration.org/media/k2/attachments/ EGM008 SWCG_Ruane-McAteer_Protocol.pdf [Accessed July 2018]

38. Bank W. World Bank Country and Lending Groups Country Classification [Internet], 2018. Available: https://datahelpdesk worldbank.org/knowledgebase/articles/906519

39. Shea BJ, Reeves BC, Wells G, et al. AMSTAR 2: a critical appraisal tool for systematic reviews that include randomised or non- 
randomised studies of healthcare interventions, or both. BMJ 2017;358.

40. Bakrania S, Ghimire A, Balvin N. Bridging the gap to understand effective interventions for Adolecent well-being: an evidence gap map on protection, participation and financial and material wellbeing in low- and middle-income countries 2017.

41. Hartmann M, Khosla R, Krishnan S, et al. How are gender equality and human rights interventions included in sexual and reproductive health programmes and policies: a systematic review of existing research foci and gaps. PLoS One 2016;11:e0167542. [Internet].

42. Krishnaratne S, Hensen B, Cordes J, et al. Interventions to strengthen the HIV prevention cascade: a systematic review of reviews. Lancet HIV 2016;3:e307-17.

43. Arango DJ, Morton M, Gennari F, et al. Interventions to prevent or reduce violence against womena and girls: a systematic review of reviews. Women's Voices Agency Res Ser 2014;10:0-60.

44. Anderson JC, Campbell JC, Farley JE. Interventions to address HIV and intimate partner violence in sub-Saharan Africa: a review of the literature. Journal of the Association of Nurses in AIDS Care 2013;24:383-90.

45. Small E, Nikolova SP, Narendorf SC. Synthesizing gender based HIV interventions in Sub-Sahara Africa: a systematic review of the evidence. AIDS Behav 2013;17:2831-44.

46. Lopez LM, Tolley EE, Grimes DA, et al. Theory-based strategies for improving contraceptive use: a systematic review. Contraception 2009;79:411-7.

47. Sarkar A, Chandra-Mouli V, Jain K, et al. Community based reproductive health interventions for young married couples in resource-constrained settings: a systematic review. BMC Public Health 2015;15. [Internet].

48. Kraft JM, Wilkins KG, Morales GJ, et al. An evidence review of gender-integrated interventions in reproductive and maternal-child health. J Health Commun 2014;19:122-41. [Internet].

49. Tokhi M, Comrie-Thomson L, Davis J, et al. Involving men to improve maternal and newborn health: a systematic review of the effectiveness of interventions. PLoS One 2018;13:e0191620. [Internet].

50. Feder L, Wilson DB, Austin S. Court-mandated interventions for individuals convicted of domestic violence. Campbell Syst Rev 2008; 12 .

51. Smith V, Devane D, Begley CM, et al. Methodology in conducting a systematic review of systematic reviews of healthcare interventions. BMC Med Res Methodol 2011;11.

52. Burrell SR. The contradictory possibilities of engaging men and boys in the prevention of men's violence against women in the UK. Journal of Gender-Based Violence 2018;2:447-64.

53. Arias $\mathrm{E}$, Arce R, Vilariño M. Batterer intervention programmes: a meta-analytic review of effectiveness. Psychosocial Intervention 2013;22:153-60.

54. Bacchus LJ, Colombini M, Contreras Urbina M, et al. Exploring opportunities for coordinated responses to intimate partner violence and child maltreatment in low and middle income countries: a scoping review. Psychol Health Med 2017;22:135-65.

55. Bourey C, Williams W, Bernstein EE, et al. Systematic review of structural interventions for intimate partner violence in low- and middle-income countries: organizing evidence for prevention. BMC Public Health 2015;15:1165.

56. Casey E, Carlson J, Two Bulls S, et al. Gender transformative approaches to engaging men in gender-based violence prevention: a review and conceptual model. Trauma Violence Abuse 2018;19:246.

57. Chatterjee K. What could work to prevent child marriages and delay pregnancy during adolescence in India: a systematic review of evidences from low and middle income countries. Eur Acad Res 2015;III:1458-90.

58. DeGue S, Valle LA, Holt MK, et al. A systematic review of primary prevention strategies for sexual violence perpetration. Aggress Violent Behav 2014;19:346-62.

59. Denison E, Berg RC, Lewin S, et al. Effectiveness of interventions designed to reduce the prevalence of female genital mutilation/ cutting [Internet]. Kunnskapssenteret Norwegian Knowledge Center for the Health Services. Oslo 2009.

60. Ellsberg M, Arango DJ, Morton M, et al. Prevention of violence against women and girls: what does the evidence say? The Lancet 2015;385:1555-66

61. Gibbs A, Willan S, Misselhorn A, et al. Combined structural interventions for gender equality and livelihood security: a critical review of the evidence from southern and eastern Africa and the implications for young people. J Int AIDS Soc 2012;15(Suppl 1):17362.

62. Haberland NA. The case for addressing gender and power in sexuality and HIV education: a comprehensive review of evaluation studies. Int Perspect Sex Reprod Health 2015;41:31-42.

63. Harrison A, Newell M-L, Imrie J, et al. Hiv prevention for South African youth: which interventions work? A systematic review of current evidence. BMC Public Health 2010;10. [Internet].

64. Heise L. What works to prevent partner violence? An evidence overview [Internet]. London, UK, 2011. Available: http:// researchonline.Ishtm.ac.uk/21062/

65. Jennings WG, Okeem C, Piquero AR, et al. Dating and intimate partner violence among young persons ages 15-30: evidence from a systematic review. Aggress Violent Behav 2017. [Internet].

66. Jewell LM, Wormith JS. Variables associated with attrition from domestic violence treatment programs targeting male batterers. Crim Justice Behav 2010;37:1086-113. [Internet].

67. Keleher H, Franklin L. Changing gendered norms about women and girls at the level of household and community: a review of the evidence. Glob Public Health 2008;3:42-57. [Internet].

68. LaCroix JM, Pellowski JA, Lennon CA, et al. Behavioural interventions to reduce sexual risk for HIV in heterosexual couples: a meta-analysis. Sex Transm Infect 2013;89:620-7. [Internet].

69. McCloskey LA, Boonzaier F, Steinbrenner SY, et al. Determinants of intimate partner violence in sub-Saharan Africa: a review of prevention and intervention programs. Partner Abuse 2016;7:277-315. [Internet].

70. Muralidharan A, Fehringer J, Pappa S, et al. Roles, and power dynamics for evidence from a health programs in. Futures Group. Health Policy Project. Washington DC 2015.

71. Mavedzenge SN, Doyle A, Ross D. Hiv prevention in young people in sub-Saharan Africa: a systematic review. London, UK, 2010.

72. Rankin K, Jarvis-Thiébault J, Pfeifer N, et al. Adolescent sexual and reproductive health an evidence gap MAP 2016

73. Rees K, Zweigenthal V, Joyner K. Health sector responses to intimate partner violence: a literature review. African J Prim Heal Care Fam Med [Internet] 2014;6.

74. Remme M, Siapka M, Vassall A, et al. The cost and costeffectiveness of gender-responsive interventions for HIV: a systematic review. J Int AIDS Soc 2014;17:19228.

75. Ricardo C, Eads M, Barker GT. Engaging boys and young men in the prevention of sexual violence: a systematic and global review of evaluated interventions. sexual violence research initiative and Promundo. Pretoria, South Africa 2011.

76. Schriver B, Mandal M, Muralidharan A, et al. Gender counts: a systematic review of evaluations of gender-integrated health interventions in low- and middle-income countries. Glob Public Health 2017;12:1335-50.

77. Skevington SM, Sovetkina EC, Gillison FB. A Systematic Review to Quantitatively Evaluate 'Stepping Stones': A Participatory Community-based HIV/AIDS Prevention Intervention. AIDS Behav 2013;17:1025-39. [Internet].

78. Smedslund G, Dalsbø T, Steiro A, et al. Cognitive behavioural therapy for men who physically abuse their female partner Cochrane Database of Systematic Reviews - Smedslund - Wiley Online Library. Cochrane Database Syst Rev 2011;(2). [Internet].

79. Storer HL, Casey E, Herrenkohl T. Efficacy of bystander programs to prevent dating abuse among youth and young adults: a review of the literature. Trauma, Violence, Abus 2015. 